\title{
Co-limitation by iron and light of Chaetoceros brevis, C. dichaeta and C. calcitrans (Bacillariophyceae)
}

\author{
Klaas R. Timmermans ${ }^{1, *}$, Margaret S. Davey ${ }^{2}$, Bas van der Wagt ${ }^{1}$, Josje $\operatorname{Snoek}^{1}$, \\ Richard J. Geider $^{2, * *}$, Marcel J. W. Veldhuis ${ }^{1}$, Loes J. A. Gerringa ${ }^{1}$, \\ Hein J. W. de Baar ${ }^{1}$
}

${ }^{1}$ Netherlands Institute for Sea Research, Department of Marine Chemistry and Geology, PO Box 59, 1790 AB Den Burg, Texel, The Netherlands

${ }^{2}$ Marine Biological Association, The Laboratory, Citadel Hill, Plymouth PL1 2PB, United Kingdom

\begin{abstract}
The interaction between iron and light limitation was investigated in 3 marine diatom species: 2 Antarctic diatom isolates, Chaetoceros brevis and C. dichaeta, and an isolate from temperate waters, C. calcitrans. In C. calcitrans and C. brevis, grown in the laboratory using trace metal buffered medium, both iron and light limitation affected growth rates, cellular chlorophyll a fluorescence, spinal index (i.e., the number and size of spines) and cell size. Growth rates and cell size declined at lower iron concentrations and lower light intensities. Cellular chlorophyll a fluorescence increased with lower light, but decreased due to iron limitation. The spinal index, based on the ratio of side scatter to forward scatter, increased in iron- and light-limited cells. The large diatom $C$. dichaeta, grown in natural Southern Ocean water (without ethelenediaminetetraacetic acid [EDTA]) showed qualitatively similar responses to co-limitation by iron and light. C. dichaeta only grew under long-day light conditions. This response was further modified by the availability of iron. Addition of iron resulted in higher growth rates. In contrast, ambient iron concentrations did not limit the growth rate of the small Antarctic diatom C. brevis. However, iron limitation could be induced by addition of the natural iron binding ligand desferrioxamine B (DFOB). Addition of iron to Fe-depleted cultures of C. dichaeta and C. brevis reversed the effects of DFOB, as evidenced by rapid increases (within $24 \mathrm{~h}$ ) in photochemical quantum efficiency $\left(F_{\mathrm{v}} / F_{\mathrm{m}}\right)$ and decreases in effective absorption of the crosssection of photosystem II $\left(\sigma_{\mathrm{PSII}}\right)$, the turnover time of the photosynthetic unit $(\tau)$ and the electron transfer rate $(1 / \tau)$, followed by an increase in growth rates after $48 \mathrm{~h}$. The interactions between iron and light in Antarctic diatoms are sufficient to explain the observation that in the Southern Ocean some species (i.e., the small $C$. brevis) thrive under low iron and low light conditions, whereas other species (i.e., the large C. dichaeta) can bloom only under conditions of relatively high iron concentrations and favorable high light intensities or a long-day light period. These differences in physiological responses will have consequences for primary production, the carbon cycle and biogeochemical cycles.
\end{abstract}

KEY WORDS: Marine diatoms $\cdot$ Iron $\cdot$ Light $\cdot$ Co-limitation $\cdot$ Growth rates $\cdot$ Fluorescence $\cdot$ Cell size $\cdot$ Chaetoceros calcitrans $\cdot$ C. brevis $\cdot$ C. dichaeta

Resale or republication not permitted without written consent of the publisher

\section{INTRODUCTION}

Iron and light may co-limit primary production in vast areas of the world's oceans. For photoautotrophs, light is the primary and often only source of energy.

\footnotetext{
*E-mail: klaas@nioz.nl

** Present address: Department of Biological Sciences, University of Essex, Colchester CO4 3SQ, United Kingdom
}

The penetration and intensity of the light in the water column determines the volume in which photosynthesis can take place (Mitchell et al. 1991, Nelson \& Smith 1991). Similarly, iron is indispensable for many major biochemical processes, including photosynthesis. The majority of the required iron ( 70 to $80 \%$ ) in phytoplankton is needed in the photosynthetic electron transport (PET) chain (Raven 1990). As a consequence, iron limitation is most readily observed in the photo- 
synthetic apparatus (Greene et al. 1994). Iron greatly affects the rate of light utilisation by phytoplankton (Raven 1990) and thus primary productivity (Geider \& LaRoche 1994). Diagnosis of Fe limitation in marine phytoplankton can therefore be done based on variations in the photochemical energy conversion efficiency of photosystem II (PS II) (Behrenfeld et al. 1996), using the concentration or activity of components of the PET chain (Kolber et al. 1994, Behrenfeld \& Kolber 1999). Given the strong biological coupling between availability of iron and light and their effects on phytoplankton growth rates and the accumulation of phytoplankton biomass, co-limitation is likely to occur (Maldonado et al. 1999). This would be possible in so-called high nutrient, low chlorophyll (HNLC) regions, for example, the Southern Ocean, since there is ample evidence for both iron limitation (de Baar et al. 1995, Timmermans et al. 1998, Boyd et al. 2000) and light limitation (Mitchell et al. 1991, Behrenfeld \& Kolber 1999) of phytoplankton photosynthesis. The exact impact of both iron and light limitation may be variable as species-specific differences in responses to iron and light availability seem to exist (Sunda \& Huntsman 1997, Henley \& Lin 1998).

The interaction between iron and light was examined in 3 diatom species: Chaetoceros calcitrans, a temperate isolate, and C. brevis and C. dichaeta, both Antarctic isolates. Apart from their origin of collection and thus temperature preference, the species differed also in size and morphology: C. calcitrans and C. brevis are small (4 to $6 \mu \mathrm{m}$ diameter) single-cell species, $C$. dichaeta is a large (60 to $80 \mu \mathrm{m}$ diameter), chain-forming species with long (up to $100 \mu \mathrm{m}$ ) spines. The colimitation by iron and light was examined in the laboratory using seawater amended with the artificial chelator ethelenediaminetetraacetic acid (EDTA), and in unamended Southern Ocean seawater in order to examine growth under more natural conditions. Stateof-the-art metal speciation calculations were combined with fast repetition rate fluorometry, flow cytometry and light microscopy. Insight into the effects of iron and light limitation can lead to a better understanding of phytoplankton growth in the Southern Ocean and their effect on the carbon and other biogeochemical cycles.

\section{MATERIAL AND METHODS}

Algal strains and culture conditions. Chaetoceros calcitrans (CCMP1315), C. brevis (CCMP 163) and C. dichaeta were obtained from the NIOZ culture collection. Unialgal cultures were grown under batch conditions in polycarbonate square bottles (125 or $250 \mathrm{ml}$ ). Rigorous precautions were taken to prevent trace metal contamination. Rinsing and subsequent handling of all materials coming in contact with the growth medium were done under trace metal clean conditions. Prior to use, the culturing bottles were cleaned for $24 \mathrm{~h}$ in $1 \mathrm{~N} \mathrm{HCl}$, followed by triple rinsing with deionised (Milli-Q) water. Finally, the bottles were sterilized using boiling de-ionised water. This procedure resulted in trace-metal-clean, sterile bottles. Cell counts and cell properties (size, fluorescence, spines/cell surface) of $C$. brevis and C. calcitrans cultures were analysed using a Coulter XL flow cytometer. C. dichaeta was inspected microscopically (numbers, cells per chain, dimension per cell) in $4 \mathrm{ml}$ settling chambers using a Zeiss Axiovert 25 inverted microscope.

Laboratory experiments. Chaetoceros calcitrans and C. brevis: Aged natural seawater was used as medium. The seawater was collected under clean conditions in the Gulf of Biscay in September 1998 and prepared for use as growth medium. The seawater was filter sterilized using Sartorius Sartobran filter capsules ( $0.07 \mu \mathrm{m}$ nominal size cut-off). Then, under trace metal clean and sterile conditions, major nutrients were added: phosphate $\left(6.5 \times 10^{-6} \mathrm{M}\right)$, silicate $\left(100 \times 10^{-6} \mathrm{M}\right)$ and nitrate $\left(100 \times 10^{-6} \mathrm{M}\right.$, all final concentrations). As commercially available reagent grade silicate is highly contaminated with $\mathrm{Fe}$, a home-made solution of silicate was used. Elemental Si was dissolved at elevated temperature and pressure in concentrated nitric acid. Thus a combination of silicate and nitrate was made. The acidic nature of this mixture made it necessary to use $\mathrm{NaOH}$ (Suprapure) to neutralize $\mathrm{pH}$. The $\mathrm{pH}$ of the medium at the start of the experiments was 8.0 to 8.2. A mix of 3 essential vitamins was added: biotin $(0.16 \times$ $\left.10^{-9} \mathrm{M}\right)$, thiamine- $\mathrm{HCl}\left(59 \times 10^{-9} \mathrm{M}\right)$ and $\mathrm{B} 12(0.59 \times$ $10^{-9} \mathrm{M}$ ). Finally, a mixture of zinc, cobalt, copper, molybdenum, selenium and manganese was added giving final concentrations of $10 \times 10^{-9}, 20 \times 10^{-9}, 40 \times$ $10^{-9}, 1.43 \times 10^{-9}, 100 \times 10^{-9}$ and $450 \times 10^{-9} \mathrm{M}$, respectively, and a trace element mixture $\left(\mathrm{KBr}: 92 \times 10^{-6} \mathrm{M}\right.$, $\mathrm{SrCl}_{2} \cdot 6 \mathrm{H}_{2} \mathrm{O}: 13 \times 10^{-6} \mathrm{M}^{-\mathrm{AlCl}_{3}}: 0.1 \times 10^{-6} \mathrm{M}, \mathrm{LiCl}:$ $0.07 \times 10^{-6} \mathrm{M}, \mathrm{KI}: 0.06 \times 10^{-6} \mathrm{M}_{1} \mathrm{H}_{3} \mathrm{BO}_{3}: 3.23 \times 10^{-6} \mathrm{M}$ and $\mathrm{RbCl}$ : $0.25 \times 10^{-6} \mathrm{M}$, final concentrations). A fixed concentration of EDTA $\left(500 \times 10^{-6} \mathrm{M}\right)$ and variable amounts of $\mathrm{FeCl}_{3}$ were added to obtain the desired range in Fe concentration. The clean handling and use of clean reagents resulted in a basic medium with relatively low trace metal concentrations. Routine measurements of the background concentrations of the most important bioactive trace metals showed that $\mathrm{Fe}$ concentrations were $8.0 \pm 0.5 \times 10^{-9} \mathrm{M}$, Zn concentrations were $10.6 \pm 3.0 \times 10^{-9} \mathrm{M}$, Co concentrations were $61 \pm 10 \times 10^{-12} \mathrm{M}, \mathrm{Cd}$ concentrations were $120 \pm 16 \times$ $10^{-12} \mathrm{M}$ (total dissolved concentrations, average $\pm \mathrm{SD}$, $\mathrm{n}=3$ ). Light was provided by cool white fluorescence tubes (Phillips, TLD 36W/54). All manipulations of the 
phytoplankton cultures were done in a Class 100 laminar flowbench.

Metal speciation in laboratory experiments: Metal speciation and complex formation were calculated by an iterative process as follows: First, the free metal concentrations were calculated based only on the formation of the inorganic complexes using the inorganic side reaction coefficient $\alpha$. Second, the metalEDTA complexes were calculated. Third, the free metal concentrations were calculated again incorporating the metal-EDTA complex into the side reaction coefficient, after which the metal-EDTA complex was calculated for the second time. This was repeated for a third time.

The speciation of Fe(III) in the culture medium at the start of the experiments was calculated using an adapted version of MINEQL ${ }^{+}$(Secher \& McAvoy 1992). $\mathrm{MINEQL}^{+}$was used to obtain conditional stability constants at a salinity of 35, with the exception of those of the dissolved Fe(III) hydroxides and the calculation of dissociation of carbonic acid. The conditional hydrolysis constants of the 4 dissolved Fe hydroxides were from Millero (1998). The carbonate concentration was calculated according to Roy et al. (1993a,b).

Speciation was calculated considering the following inorganic species: $\mathrm{Fe}^{3+}, \mathrm{Fe}(\mathrm{OH})^{2+}, \mathrm{Fe}(\mathrm{OH})_{2}{ }^{+}, \mathrm{Fe}(\mathrm{OH})_{3}{ }^{0}$, and $\mathrm{Fe}(\mathrm{OH})_{4}{ }^{-}$for $\mathrm{Fe}$ (using $K^{\prime}$ values from Millero 1998). Complexation of the Fe by dissolved natural organic ligands was not taken into account as these ligands will be outcompeted by the surplus of EDTA.

We assumed that the dissolved Fe species were in equilibrium, and that the $\alpha$ coefficients $\left(K^{\prime}\left[L^{x-}\right]\right)$ governed the distribution over the species as shown below. The mass balance of a constituent can be rewritten using the conditional stability constant

$$
K^{\prime}=\frac{\left[\mathrm{Fe} L_{n}{ }^{x-3}\right]}{\left[\mathrm{Fe}^{3+}\right]\left[L^{X^{-}}\right]^{n}}
$$

in which $L$ stands for ligand, into

$$
[\mathrm{Fe} L]=K^{\prime}\left[L^{X-}\right]^{n}\left[\mathrm{Fe}^{3+}\right]
$$

defining $\alpha_{L}$ as

$$
\alpha_{L}=K^{\prime}\left[L^{X-}\right]^{n}
$$

Substituting Eq. (3) into Eq. (2) gives

$$
[\mathrm{Fe} L]=\alpha_{L}\left[\mathrm{Fe}^{3+}\right]
$$

The mass balance

$$
\begin{gathered}
{\left[\mathrm{Fe}_{\mathrm{t}}\right]_{\text {diss }}=\left[\mathrm{Fe}^{3+}\right]+\left[\mathrm{Fe}(\mathrm{OH})^{2+}\right]+\left[\mathrm{Fe}(\mathrm{OH})_{2}{ }^{+}\right]+} \\
{\left[\mathrm{Fe}(\mathrm{OH})_{3}{ }^{0}\right]+\left[\mathrm{Fe}(\mathrm{OH})_{4}{ }^{-}\right]+[\mathrm{FeEDTA}]+} \\
{[\mathrm{Fe}(\mathrm{OH}) \mathrm{EDTA}]+\left[\mathrm{FE}(\mathrm{OH})_{2} \mathrm{EDTA}\right]}
\end{gathered}
$$

then becomes

$$
\left[\mathrm{Fe}_{\mathrm{t}}\right]_{\mathrm{diss}}=\left[\mathrm{Fe}^{3+}\right]+\alpha_{\mathrm{i}}[\mathrm{Fe}]+\alpha_{\mathrm{EDTA}}\left[\mathrm{Fe}^{3+}\right]
$$

in which $\alpha_{i}$ is called the inorganic side reaction, being the sum of the 4 inorganic $\alpha$ values and $\alpha_{\text {EDTA }}$ being the sum of the 3 side reactions of Fe with EDTA. It was assumed that Fe' (all inorganic Fe species) determined the biological response in the phytoplankton (in addition to variations in the light intensities).

In Expt A, Chaetoceros calcitrans was grown at $15^{\circ} \mathrm{C}$, at continuous light with high (HL: $200 \mu \mathrm{mol}$ photons $\mathrm{m}^{-2} \mathrm{~s}^{-1}$ ) or low (LL: $20 \mu \mathrm{mol}$ photons $\mathrm{m}^{-2} \mathrm{~s}^{-1}$ ) light intensities at continuous light and a gradient from 0.1 to $15 \times 10^{-12} \mathrm{M} \mathrm{Fe}^{\prime}$. Growth rates, cellular chlorophyll a fluorescence (standardised per cell size), forward scatter (FS, approximation of cell size) and spinal index (ratio of side scatter [SS] per FS) were determined (Table 1).

In Expt BI, Chaetoceros brevis was grown at $4^{\circ} \mathrm{C}$, at high (HL: $60 \mu \mathrm{mol}$ photons $\mathrm{m}^{-2} \mathrm{~s}^{-1}$ ) or low (LL: $15 \mu \mathrm{mol}$ photons $\mathrm{m}^{-2} \mathrm{~s}^{-1}$ ) light intensities in a 16:8 h light:dark regime, and a gradient of 0.1 to $50 \times 10^{-12} \mathrm{M} \mathrm{Fe}^{\prime}$. In the parallel Expt BII, under iron-replete conditions, the effects of HL and LL conditions on growth rates, cellular autofluorescence, forward scatter and spinal index were determined in C. brevis (Table 1).

Shipboard experiments. Chaetoceros brevis and $C$. dichaeta: During the ANT XVI/3 expedition (RV 'Polarstern', March 18 to May 10, 1999) in the Southern Ocean, C. brevis and C. dichaeta were grown in freshly collected filtered $(0.2 \mu \mathrm{m})$ seawater without addition of artificial (iron) complexing agents or major nutrients. Seawater south of the Polar Front with silicate concentrations above $15 \times 10^{-6} \mathrm{M}$ and nitrate concentrations above $20 \times 10^{-6} \mathrm{M}$ was collected and treated using clean sampling and handling techniques (de Jong et al. 1998). Dissolved iron ( $\left.\mathrm{Fe}_{\text {diss }}\right)$ concentrations were $0.2 \times 10^{-9} \mathrm{M}$. Light was provided by cool white fluorescence tubes (Phillips, TLD 36W/54). All manipulations of the phytoplankton cultures were done in a Class 100 laminar flowbench.

The effects of light and iron were assessed based on growth rates of the phytoplankton in response to dissolved iron concentrations (or addition of desferrioxamine B [DFOB], see below) and light intensity in experiments only slightly different from the first set of laboratory experiments. The necessary cell counts for the calculation of the specific growth rates (and thus maximum specific growth rates $\left[\mu_{\max }\right]$ and half-saturation values $\left.\left[K_{\mathrm{m}}\right]\right)$, as well as cell size and cellular chlorophyll a fluorescence were made using a flow cytometer (Chaetoceros brevis) or using a microscope (C. dichaeta). Both species were further probed using fast repetition rate fluorometry (FRRF). The principles of the FRRF fluorescence method are described in Kolber et al. (1994). Briefly, fluorescence was measured using a Chelsea Instruments FAST ${ }^{\text {tracker }}$ (Chelsea Instruments Ltd, West Molesey, Surrey, UK). FRRF was 
Table 1. Overview of the experiments. EDTA: ethelenediaminetetraacetic acid; DFOB: desferrioxamine B. HL, LL: high or low light. Flow cytometer parameters: SS: side scatter; FS: forward scatter; FL3: chlorophyll a autofluorescence

\begin{tabular}{|c|c|c|c|c|c|c|}
\hline Species & Expt & $\begin{array}{c}\mathrm{Fe}^{\prime} \\
\left(\times 10^{-12} \mathrm{M}\right)\end{array}$ & $\begin{array}{c}\text { EDTA } \\
\left(\times 10^{-6} \mathrm{M}\right)\end{array}$ & $\begin{array}{c}\text { Light intensity } \\
\left(\mu \mathrm{mol} \text { photons } \mathrm{m}^{-2} \mathrm{~s}^{-1}\right)\end{array}$ & $\begin{array}{l}\text { Light period } \\
\text { (L:D, h) }\end{array}$ & Parameters \\
\hline \multicolumn{7}{|l|}{ Laboratory experiments } \\
\hline Chaetoceros calcitrans & ; A & $0.1-15$ & 500 & HL: 200, LL: 20 & $24: 0$ & Numbers, FS, SS, FL3 \\
\hline \multirow[t]{2}{*}{ Chaetoceros brevis } & BI & $0.1-50$ & 500 & HL: 60, LL: 15 & $16: 8$ & Numbers \\
\hline & BII & $>20$ & 500 & HL: 60, LL: 15 & $16: 8$ & Numbers, FS, SS, FL3 \\
\hline Species & Expt & $\begin{array}{c}\mathrm{Fe}_{\text {diss }} \\
\left(\times 10^{-9} \mathrm{M}\right)\end{array}$ & $\begin{array}{c}\text { DFOB } \\
\left(\times 10^{-9} \mathrm{M}\right)\end{array}$ & $\begin{array}{c}\text { Light intensity } \\
\left(\mu \mathrm{mol} \text { photons } \mathrm{m}^{-2} \mathrm{~s}^{-1}\right)\end{array}$ & $\begin{array}{l}\text { Light period } \\
\quad(\mathrm{L}: \mathrm{D}, \mathrm{h})\end{array}$ & Parameters \\
\hline \multicolumn{7}{|l|}{ Shipboard experiments } \\
\hline \multirow[t]{5}{*}{ Chaetoceros dichaeta } & CI & $0.2-8.2$ & - & 80 & $12: 12$ & Numbers \\
\hline & CII & $0.2-8.2$ & - & 80 & $20: 4$ & Numbers \\
\hline & CIII & 0.2 & - & 80 & $20: 4$ & Numbers, $F_{\mathrm{v}} / F_{\mathrm{m}}, \sigma_{\mathrm{PSII}}, \tau$ \\
\hline & & 2.2 & - & 80 & $20: 4$ & Numbers, $F_{\mathrm{v}} / F_{\mathrm{m}}, \sigma_{\mathrm{PSII}}, \tau$ \\
\hline & & 0.2 & 7.0 & 80 & $20: 4$ & Numbers, $F_{\mathrm{v}} / F_{\mathrm{m}}, \sigma_{\mathrm{PSII}}, \tau$ \\
\hline \multirow[t]{3}{*}{ Chaetoceros brevis } & $\mathrm{D}$ & 0.2 & - & 80 & $12: 12$ & Numbers, $F_{\mathrm{v}} / F_{\mathrm{m}}$ \\
\hline & & 2.2 & - & 80 & $12: 12$ & Numbers, $F_{\mathrm{v}} / F_{\mathrm{m}}$ \\
\hline & & 0.2 & 7.0 & 80 & $12: 12$ & Numbers, $F_{\mathrm{v}} / F_{\mathrm{m}}$ \\
\hline \multirow[t]{3}{*}{ Chaetoceros brevis } & EI & 0.2 & - & 80 & $12: 12$ & Numbers, FL3 \\
\hline & EII & 0.2 & - & $80 \rightarrow 20$ & $12: 12$ & Numbers, FL3 \\
\hline & EIII & 0.2 & 7.0 & $80 \rightarrow 20$ & $12: 12$ & Numbers, FL3 \\
\hline
\end{tabular}

used to determine the ratio of variable to maximum fluorescence $\left(F_{\mathrm{v}} / F_{\mathrm{m}}\right)$, as well as determination of the effective cross-section of PS II $\left(\sigma_{\mathrm{PSII}}\right)$, the turnover time $(\tau)$ and electron transfer rate $(1 / \tau) .{ }^{1}$ Samples were removed daily for these measurements and preconditioned in the dark for $30 \mathrm{~min}$ prior to analysis. The samples were transferred into a measuring chamber that was placed in the light path of the instrument. Whilst $F_{\mathrm{m}}$ provided an index of chlorophyll concentrations, $F_{\mathrm{v}}$ was used to indicate the abundance of functional PSII reaction centres. The ratio of variable to maximum fluorescence is indicative of PSII efficiency, which itself is dependent upon the nutritional (iron) status of the phytoplankton cells (Geider \& LaRoche 1994). $\sigma_{\mathrm{PSII}}$ is a less commonly used biophysical diagnostic index of nutrient limitation, with values increasing under iron limitation (Greene et al. 1991). The value of $\tau$, the turnover time, indicates the time taken for electron transport through the PET, and is governed by the slowest electron transfer reaction from $\mathrm{H}_{2} \mathrm{O}$ to the terminal electron acceptor (e.g., $\mathrm{CO}_{2}$ ) (Myers \& Graham 1971). Whilst this rate-limiting step in the overall pathway has been the subject of speculation (summarised by Falkowski \& Raven 1997), changes in the abundance of components of the PET, occurring as a result of nutrient deficiency, may increase $\tau$ values (and hence decrease 1/ $\tau$ ) (Greene et al. 1991).

In Expt C, Chaetoceros dichaeta was grown over a range of $\mathrm{Fe}$ additions, both in a short-day (Expt $\mathrm{CI}$, 12:12 h light:dark) and in a long-day (Expt CII, 20:4 h light:dark) light regime. Moreover, $F_{\mathrm{v}} / F_{\mathrm{m}}, \sigma_{\mathrm{PSII}}, \tau$ (and $1 / \tau)$ were determined in a control culture $\left(\mathrm{Fe}_{\text {diss }} 0.2 \times\right.$ $10^{-9} \mathrm{M}$ ), a culture with $2.0 \times 10^{-9} \mathrm{M}$ Fe addition and a culture amended with $7.0 \times 10^{-9} \mathrm{M}$ DFOB (Expt CIII, Table 1). The addition of DFOB, a strong iron-binding ligand $\left(\log K^{\prime}\right.$ of 24.5; E. Rue, University of California, Santa Cruz, USA, pers. comm.) lowered available Fe concentrations below ambient levels.

In Expt D, changes in $F_{\mathrm{v}} / F_{\mathrm{m}}$ in Chaetoceros brevis in response to iron addition and iron deprivation were quantified using FRRF. In these experiments, $C$. brevis was grown in a culture with background Fe concentrations (control, $0.2 \times 10^{-9} \mathrm{M} \mathrm{Fe}_{\text {diss }}$ ), a culture receiving a $2.0 \times 10^{-9} \mathrm{M}$ Fe addition, and a culture receiving a $7.0 \times$ $10^{-9} \mathrm{M}$ DFOB addition. DFOB addition was necessary for $C$. brevis, as it was shown in previous experiments that this species was not iron limited at the ambient $\mathrm{Fe}_{\text {diss }}$ of $0.2 \times 10^{-9} \mathrm{M}$ in the Southern Ocean seawater used (Timmermans et al. 2001). Flow cytometry was used in the same experiment to quantify the effects on growth rates (Table 1 ).

In Expt E, the responses of Chaetoceros brevis to variations in light intensity (HL and LL: 80 and $20 \mu \mathrm{mol}$ photons $\mathrm{m}^{-2} \mathrm{~s}^{-1}$ ) were studied in relation to varying iron concentrations. The culture originally grown at standard HL conditions was divided into 3 bottles (Expts EI-III). Bottle EI had ambient Fe $\mathrm{e}_{\text {diss }}$ concentration $\left(0.2 \times 10^{-9} \mathrm{M}\right)$ and standard HL $(80 \mu \mathrm{mol}$ photons $\mathrm{m}^{-2} \mathrm{~s}^{-1}$ ). Bottle EII was transferred to reduced light (LL: $20 \mu \mathrm{mol}$ photons $\mathrm{m}^{-2} \mathrm{~s}^{-1}$ ) without modifying the 
iron concentration $\left(\mathrm{Fe}_{\text {diss }}\right.$ : $0.2 \times 10^{-9} \mathrm{M}$ ). Bottle EIII was transferred to reduced light (LL: $20 \mu \mathrm{mol}$ photons $\mathrm{m}^{-2}$ $\mathrm{s}^{-1}$ ), and also had reduced available iron concentration by addition $7.0 \times 10^{-9} \mathrm{M}$ DFOB. The effects of variation in light and iron concentration were assessed using cell counts (growth rates) and changes in cellular chlorophyll a fluorescence as parameters. Towards the end of the experiment the effect of addition of DFOB was countered by addition of $10 \times 10^{-9} \mathrm{M}$ Fe (Table 1 ).

\section{RESULTS}

\section{Laboratory experiments}

Growth rates of Chaetoceros calcitrans varied as a function of $\mathrm{Fe}^{\prime}$ at both $200 \mu \mathrm{mol}$ photons $\mathrm{m}^{-2} \mathrm{~s}^{-1}$ (HL) and $20 \mu \mathrm{mol}$ photons $\mathrm{m}^{-2} \mathrm{~s}^{-1}$ (LL) intensities (Expt $\mathrm{A}$, Fig. 1A). Besides a moderate reduction in $\mu_{\max }$ (HL: $0.96 \mathrm{~d}^{-1}$ to LL: $0.70 \mathrm{~d}^{-1}$ ), $K_{\mathrm{m}}$ values for growth doubled between high and low light (HL: $K_{\mathrm{m}}$ of $0.75 \times 10^{-12} \mathrm{M}$ $\mathrm{Fe}^{\prime}, \mathrm{LL}: K_{\mathrm{m}}$ of $1.5 \times 10^{-12} \mathrm{M} \mathrm{Fe}$ ).

In addition, forward scatter ( $\mathrm{FS}$; approximation of cell size) showed distinct differences (Fig. 1B). In HL conditions Chaetoceros calcitrans FS declined with decreases in Fe'. However, Fe' did not greatly affect cell size under low light. Generally, cells were smaller in LL conditions than in HL conditions. At the lowest iron concentrations, cell sizes in the HL and LL cultures were about equal.

Cells grown in the LL cultures had about 3 times higher chlorophyll a fluorescence than those grown in HL cultures (Fig. 1C). Availability of iron also modified the chlorophyll a fluorescence signal. In both light
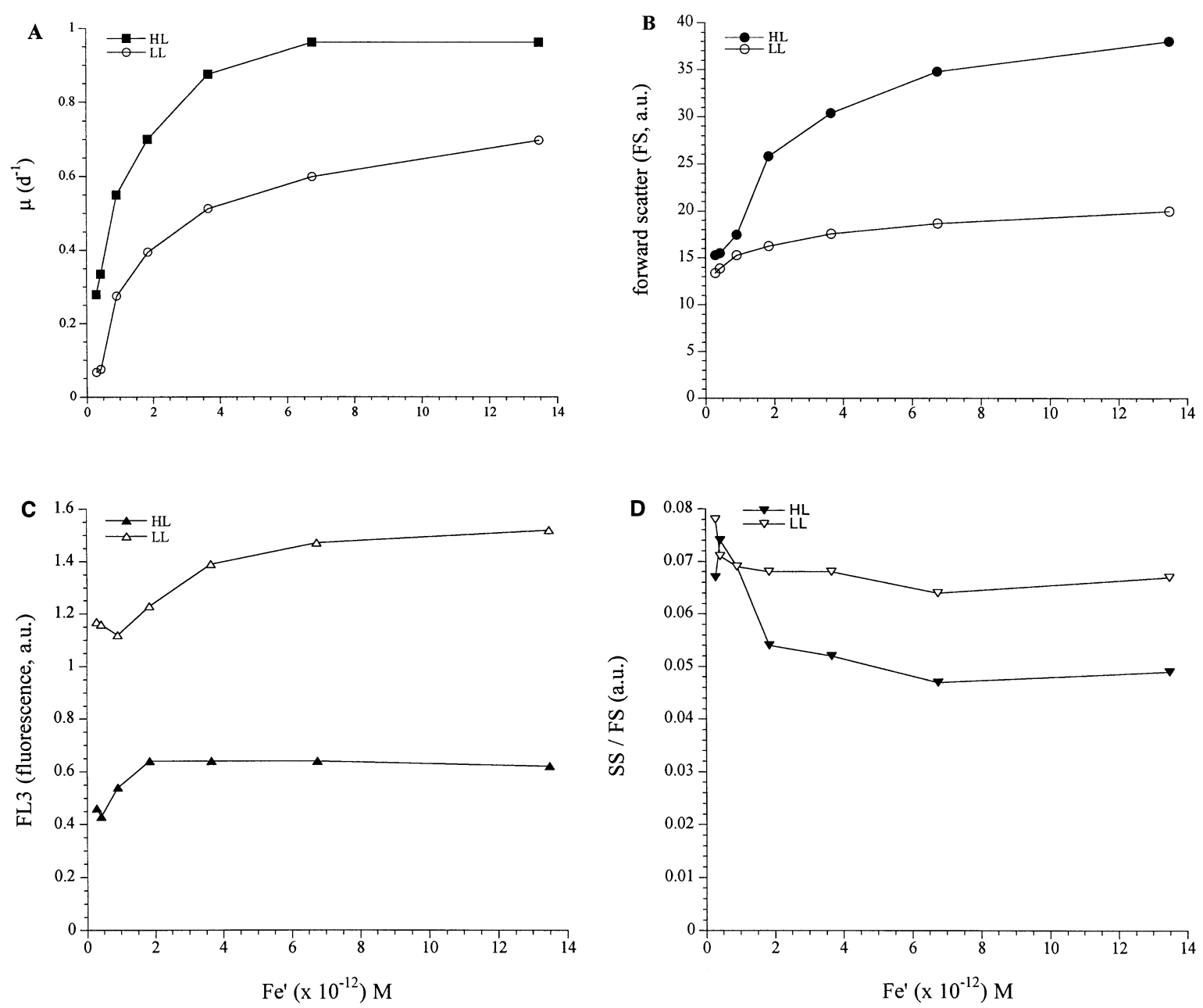

Fig. 1. Chaetoceros calcitrans (Expt A) under HL $\left(200 \mu \mathrm{mol}\right.$ photons $\left.\mathrm{m}^{-2} \mathrm{~s}^{-1}\right)$ and LL $\left(20 \mu \mathrm{mol}\right.$ photons $\left.\mathrm{m}^{-2} \mathrm{~s}^{-1}\right)$ conditions (continuous light). (A) Growth rate $(\mu)$ vs Fe'. (B) Flow cytometer parameter forward scatter (FS, approximation of the particle size) vs $\mathrm{Fe}^{\prime}$. (C) Flow cytometer parameter FL3 (approximation of chlorophyll a autofluorescence), standardised per FS (approximation of the particle size) vs Fe'. (D) Flow cytometer parameters side scatter (SS), normalised per FS used for the calculation of a spinal index 
regimes chlorophyll fluorescence gradually dropped with decreasing $\mathrm{Fe}^{\prime}$ concentrations. The decrease in fluorescence was observed at higher $\mathrm{Fe}^{\prime}$ concentrations in the LL cultures than in the HL conditions.

Based on the ratio of side scatter (SS) to FS, a spinal index was calculated. A straightforward response in relation to iron concentration and light intensity was observed in Chaetoceros calcitrans (Fig. 1D). With ample light and iron, the spinal index of the cells decreased compared to the iron-/light-limited cells.

Chaetoceros brevis showed nearly identical responses to iron and light co-limitation. Maximum growth rates varied from $0.53 \mathrm{~d}^{-1}$ at $60 \mu \mathrm{mol}$ photons $\mathrm{m}^{-2} \mathrm{~s}^{-1}$ (HL) to $0.27 \mathrm{~d}^{-1}$ at $15 \mu \mathrm{mol}$ photons $\mathrm{m}^{-2} \mathrm{~s}^{-1}$ (LL) under iron-replete conditions (Expt BI, Fig. 2). With decreasing $\mathrm{Fe}^{\prime}$ concentrations, the growth rates dropped in both the HL and LL cultures. Under HL conditions, the $K_{\mathrm{m}}$ for growth was $2 \times 10^{-12} \mathrm{M} \mathrm{Fe}^{\prime}$. The $K_{\mathrm{m}}$ for growth could not be calculated properly for the LL cultures due to a lack of data at the lower end of the growth curve, but it was estimated to be lower than $2 \times 10^{-12} \mathrm{M} \mathrm{Fe}^{\prime}$.

The growth rates of Fe-replete Chaetoceros brevis were slightly higher in Expt BII (Table 2). Growth rates in LL cultures were $40 \%$ lower than in the HL cultures. FS, which provides a measure of cell size, increased at the higher irradiance, but red autofluorescence (FL3) which provides a measure of cell chlorophyll a content declined (Table 2). These are the expected responses for photoacclimation to high irradiance. As in the previous experiment with $C$. calcitrans, the spinal index (SS/FS) was higher in the LL cultures of C. brevis.

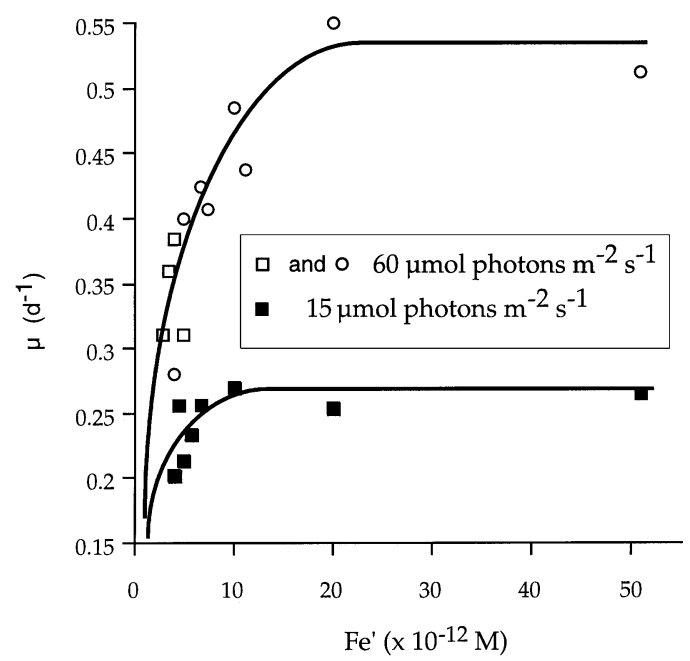

Fig. 2. Chaetoceros brevis: $\mu$ vs Fe' (Expt BI) under HL $\left(60 \mu \mathrm{mol}\right.$ photons $\left.\mathrm{m}^{-2} \mathrm{~s}^{-1}\right)$ and LL $\left(15 \mu \mathrm{mol}\right.$ photons $\left.\mathrm{m}^{-2} \mathrm{~s}^{-1}\right)$ conditions in a 16:8 $\mathrm{h}$ light:dark regime. In the HL experiment, 2 data sets were combined: ( $\square$ ) experimental results $<5 \times 10^{-12} \mathrm{M} \mathrm{Fe}^{\prime},(\mathrm{O})$ experimental results $>5 \times 10^{-12} \mathrm{M} \mathrm{Fe}^{\prime}$
Table 2. Chaetoceros brevis, (Expt BII): growth rates, forward scatter (FS, 'cell size'), autofluorescence (FL3 channel from flow cytometer, 'chlorophyll a content per cell') and spinal index (ratio of SS to FS) under LL (15 $\mu \mathrm{mol}$ photons $\left.\mathrm{m}^{-2} \mathrm{~s}^{-1}\right)$ and HL $\left(60 \mu \mathrm{mol}\right.$ photons $\left.\mathrm{m}^{-2} \mathrm{~s}^{-1}\right)$ conditions and replete $\mathrm{Fe}_{\text {diss }}$ concentrations during exponential growth. Parameters are expressed as averages $(n=8) \pm S D$

\begin{tabular}{|lccc|}
\hline Parameter & Units & \multicolumn{1}{c}{ LL } & HL \\
\hline Growth rate & $\mathrm{d}^{-1}$ & $0.47 \pm 0.09$ & $0.77 \pm 0.12$ \\
Forward scatter & a.u. & $38.5 \pm 0.7$ & $42.2 \pm 0.7$ \\
Autofluorescence & a.u. & $119.4 \pm 12.9$ & $79.8 \pm 4.4$ \\
Spinal index & SS/FS ratio & $0.075 \pm 0.002$ & $0.063 \pm 0.005$ \\
\hline
\end{tabular}

\section{Shipboard experiments with single species cultures of Antarctic diatoms}

Despite several attempts, Chaetoceros dichaeta did not grow in a series of increasing $\mathrm{Fe}_{\text {diss }}$ concentrations under a 'short-day' 12:12 h light:dark regime (Expt CI, HL: $80 \mu \mathrm{mol}$ photons $\mathrm{m}^{-2} \mathrm{~s}^{-1}$ ) (no data shown). This species was only able to grow only under a typical 'long day' (20:4 h light:dark), but at relatively low light intensities (Table 3, Expt CII). Under these conditions, $\mu_{\max }$ was $0.53 \mathrm{~d}^{-1}$ and the $K_{\mathrm{m}}$ for growth was $1.1 \times$ $10^{-9} \mathrm{M} \mathrm{Fe}_{\text {diss. }}$. The morphology of the cells varied with $\mathrm{Fe}$ concentration. At higher Fe concentrations there were more cells per chain ( $>3$ cells chain ${ }^{-1}$, no data shown). Chain length dropped to less than 3 at low Fe concentrations. In general, $F_{\mathrm{v}} / F_{\mathrm{m}}$ increased with increasing $\mathrm{Fe}$ concentrations (Fe addition $>$ control $>$ DFOB, Expt CIII, Table 4). The C. dichaeta culture grown with $\mathrm{DFOB}$ had the lowest $F_{\mathrm{v}} / F_{\mathrm{m}}$ values. Upon addition of iron to the latter culture, $F_{\mathrm{v}} / F_{\mathrm{m}}$ went up within 24 to $48 \mathrm{~h}$. The $\sigma_{\text {PSII }}$ values decreased upon addition of $\mathrm{Fe}$ to the DFOB culture; $\sigma_{\mathrm{PSII}}$ values in the culture grown with Fe were the lowest (Table 4). The turnover time $(\tau)$ increased with decreasing Fe concentrations (Fe addition < control < DFOB, Table 4). In time, $\tau$ decreased after addition of Fe to the DFOB culture. Growth, in terms of cell division, was delayed compared to the response in $F_{\mathrm{v}} / F_{\mathrm{m}}$ and increased only after 48 to $72 \mathrm{~h}$ (no data shown).

Chaetoceros brevis was grown under control conditions (ambient $\left.\mathrm{Fe}_{\text {diss }}: 0.16 \mathrm{nM}\right)$ and elevated $\left(2 \times 10^{-9} \mathrm{M}\right.$ $\mathrm{Fe}$ addition) and reduced $\mathrm{Fe}$ concentrations $(7.0 \times$ $10^{-9} \mathrm{M}$ DFOB addition) (Expt D, Fig. 3). In the control and $F e$ amended culture, the highest $F_{\mathrm{v}} / F_{\mathrm{m}}$ values and growth rates were observed. Addition of DFOB caused reductions in growth rate and $F_{\mathrm{v}} / F_{\mathrm{m}}$ (Fig. 3). As for $C$. dichaeta, the effect of DFOB could be reversed by addition of iron. Full recovery of $F_{\mathrm{v}} / F_{\mathrm{m}}$ and growth rate (to values comparable to those of control / Fe amended culture) was achieved within $24 \mathrm{~h}$ following the addition of Fe. 
Table 3. Chaetoceros dichaeta: $\mathrm{Fe}_{\text {diss }}$ vs growth rates $(\mu)$ under long-day (Expt CII, 20:4 h light:dark regime, $20 \mu \mathrm{mol}$ photons $\mathrm{m}^{-2} \mathrm{~s}^{-1}$ ) light conditions. Filtered water from RV 'Polarstern' cruise ANT XVI/3, Stn 174 (69 50' S, 6 $\left.6^{\circ} 40^{\prime} \mathrm{E}\right)$, $50 \mathrm{~m}$ depth. Fe ${ }_{\text {diss }}: 0.16 \times 10^{-9} \mathrm{M}_{1} \mathrm{NO}_{3}^{-}: 22.9 \times 10^{-6} \mathrm{M}, \mathrm{SiO}_{3}{ }^{2-}$ : $49.1 \times 10^{-6} \mathrm{M}_{1} \mathrm{PO}_{4}{ }^{3-}: 1.44 \times 10^{-6} \mathrm{M}$

\begin{tabular}{|lc|}
\hline Fe additions $\left(\times 10^{-9} \mathrm{M}\right)$ & $\mu\left(\mathrm{d}^{-1}\right)$ \\
\hline 0.0 & 0.12 \\
0.5 & 0.17 \\
1.0 & 0.31 \\
1.5 & 0.40 \\
2.0 & 0.41 \\
4.0 & 0.51 \\
6.0 & 0.51 \\
8.0 & 0.53 \\
\hline
\end{tabular}

The interactions of iron and light in Chaetoceros brevis (Expt E) are shown in Fig. 4. In the control Bottle EI, with ambient Fe $\left(0.2 \times 10^{-9} \mathrm{MFe}_{\text {diss }}\right)$ and standard HL conditions, cellular autofluorescence remained fairly constant (Fig. 4A, black bars). Growth rates in this bottle were low $\left(0.10 \mathrm{~d}^{-1}\right)$. Reduced light intensity (Bottle EII) resulted in an almost instantaneous increase in cellular autofluorescence (Fig. 4A, white bars). In addition, growth rates dropped by about half of the control. Depriving $C$. brevis of Fe (addition of DFOB, E III) under reduced light intensity yielded cells with autofluorescence intermediate to the control and light-limited culture (Fig. 4A, hatched bars). Upon addition of

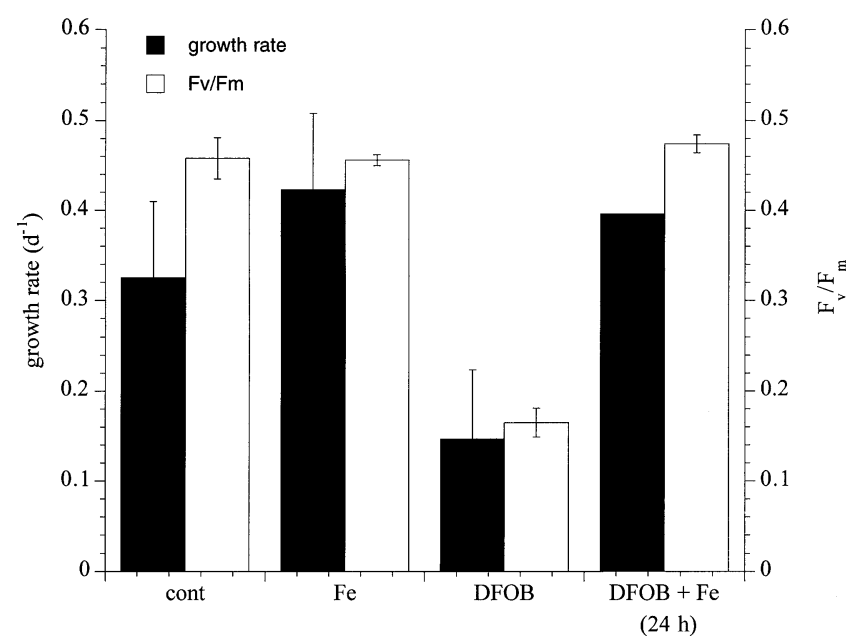

Fig. 3. Chaetoceros brevis (Expt D): $F_{\mathrm{v}} / F_{\mathrm{m}}$ (a.u.) and growth rates in control culture (cont), in a culture with $2 \times 10^{-9} \mathrm{M} \mathrm{Fe}$ addition $(\mathrm{Fe})$, and a culture with $7 \times 10^{-9} \mathrm{M}$ DFOB addition (DFOB), and the change in $F_{\mathrm{v}} / F_{\mathrm{m}}$ after $24 \mathrm{~h}$ after addition of surplus Fe $\left(10 \times 10^{-9} \mathrm{M}\right)$ to the DFOB culture. Filtered water from RV 'Polarstern' cruise ANT XVI/3, Stn 174 (69 50' S, $\left.6^{\circ} 40^{\prime} \mathrm{E}\right), 50 \mathrm{~m}$ depth. Concentrations of the nutrients at the start of the experiment were as follows: $\mathrm{Fe}_{\text {diss }}: 0.16 \times 10^{-9} \mathrm{M}$, $\mathrm{NO}_{3}: 22.9 \times 10^{-6} \mathrm{M}, \mathrm{SiO}_{3}: 49.1 \times 10^{-6} \mathrm{M}_{1} \mathrm{PO}_{4}: 1.44 \times 10^{-6} \mathrm{M}$
Table 4. Expt CIII, Chaetoceros dichaeta. $F_{\mathrm{v}} / F_{\mathrm{m}}$ (a.u.), effective cross-section of photosystem II ( $\left.\sigma_{\mathrm{PSII}}\right)(\mathrm{a} . \mathrm{u}$.), turnover time $\tau(\mathrm{ms})$ and electron transfer rate $1 / \tau\left(\mathrm{ms}^{-1}\right)$ measured in a control culture (cont), in a culture with $2 \times 10^{-9} \mathrm{M}$ Fe addition (Fe), and a culture with $7 \times 10^{-9} \mathrm{M} \mathrm{DFOB}$ addition (DFOB) at $t=0,24,48$ and $72 \mathrm{~h}$. At $t=24 \mathrm{~h}$, surplus Fe $\left(10 \times 10^{-9} \mathrm{M}\right)$ was added to the DFOB culture. FRRF measurements generated values of $F_{\mathrm{v}} / F_{\mathrm{m}}, \sigma_{\mathrm{PSII}}, \tau$ and $1 / \tau$. Each measurement consisted of 20 to 50 acquisitions; the data from each acquisition were derived from the average fluorescence results from 10 flash sequences. Data presented are average values calculated from a minimum of 6 acquisitions. SDs are calculated from the number of acquisitions averaged. The number of acquisitions used in calculating the data sets varied because only data measured at a single instrument sensitivity (gain) setting was used. Filtered water from RV 'Polarstern' cruise ANT XVI/3, Stn $174\left(69^{\circ} 50^{\prime} \mathrm{S}, 6^{\circ} 40^{\prime} \mathrm{E}\right), 50 \mathrm{~m}$ depth. Concentrations of the nutrients at the start of the experiment were as follows: $\mathrm{Fe}_{\text {diss: }}$ : $0.16 \times 10^{-9} \mathrm{M}, \mathrm{NO}_{3}: 22.9 \times 10^{-6} \mathrm{M}, \mathrm{SiO}_{3}: 49.1 \times 10^{-6} \mathrm{M}, \mathrm{PO}_{4}$ : $1.44 \times 10^{-6} \mathrm{M}$

\begin{tabular}{|c|c|c|c|}
\hline & Cont & DFOB & $\mathrm{Fe}$ \\
\hline \multicolumn{4}{|l|}{$t=0 \mathrm{~h}$} \\
\hline$F_{\mathrm{v}} / F_{\mathrm{m}}$ & $0.41 \pm 0.01$ & $0.27 \pm 0.01$ & $0.50 \pm 0.01$ \\
\hline$\sigma_{\text {PSII }}$ & $779 \pm 26$ & $1023 \pm 76$ & $632 \pm 20$ \\
\hline$\tau$ & $2629 \pm 263$ & $11874 \pm 10000$ & $2104 \pm 119$ \\
\hline $1 / \tau$ & 380 & 84 & 475 \\
\hline \multicolumn{4}{|l|}{$t=24 \mathrm{~h}$} \\
\hline$F_{\mathrm{v}} / F_{\mathrm{m}}$ & $0.40 \pm 0.01$ & $0.30 \pm 0.01$ & $0.46 \pm 0.01$ \\
\hline$\sigma_{\mathrm{PSII}}$ & $774 \pm 24$ & $1064 \pm 70$ & $629 \pm 20$ \\
\hline$\tau$ & $2939 \pm 710$ & $7426 \pm 4500$ & $2103 \pm 128$ \\
\hline $1 / \tau$ & 340 & 135 & 475 \\
\hline \multicolumn{4}{|l|}{$t=48 \mathrm{~h}$} \\
\hline$F_{\mathrm{v}} / F_{\mathrm{m}}$ & $0.36 \pm 0.01$ & $0.35 \pm 0.01$ & $0.39 \pm 0.01$ \\
\hline$\sigma_{\mathrm{PSII}}$ & $692 \pm 24$ & $833 \pm 39$ & $610 \pm 28$ \\
\hline$\tau$ & $2849 \pm 295$ & $2187 \pm 700$ & $2420 \pm 607$ \\
\hline $1 / \tau$ & 351 & 457 & 413 \\
\hline \multicolumn{4}{|l|}{$t=72 \mathrm{~h}$} \\
\hline$F_{\mathrm{v}} / F_{\mathrm{m}}$ & $0.35 \pm 0.01$ & $0.39 \pm 0.01$ & $0.42 \pm 0.01$ \\
\hline$\sigma_{\mathrm{PSII}}$ & $663 \pm 26$ & $670 \pm 24$ & $572 \pm 25$ \\
\hline$\tau$ & $3432 \pm 340$ & $2120 \pm 309$ & $2510 \pm 315$ \\
\hline $1 / \tau$ & 291 & 472 & 398 \\
\hline
\end{tabular}

$10 \times 10^{-9} \mathrm{M}$ iron to Bottle EIII, an immediate and very strong increase in fluorescence signal was observed. This rapid change in cellular autofluorescence was accompanied by a short period of population decline indicating mortality in the population (Fig. 4B). Cell

\footnotetext{
${ }^{1}$ The accuracy of the extremely high values of $\tau$ (e.g., $>5000 \mu \mathrm{s})$, seen in DFOB-treated cultures, could not be confidently assessed. The data processing provided by Chelsea Instruments appeared to assign a value to $\tau$ even when the fluorescence emissions (data not shown) showed little or no decline during the relaxation flash sequence (Kolber et al. 1998). These extremely high values should therefore be regarded as indicative of very slow turnover of the photosynthetic unit. Changes to the period and intervals in the FRRF flash sequences may have resolved these numbers more accurately, but possibly at the cost of accuracy in other parameters measured
} 


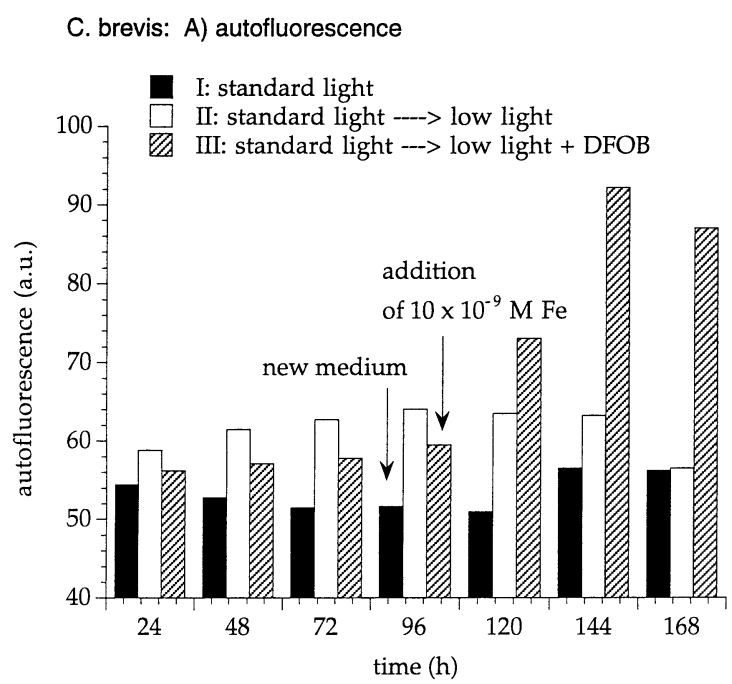

C. brevis: B) growth rates

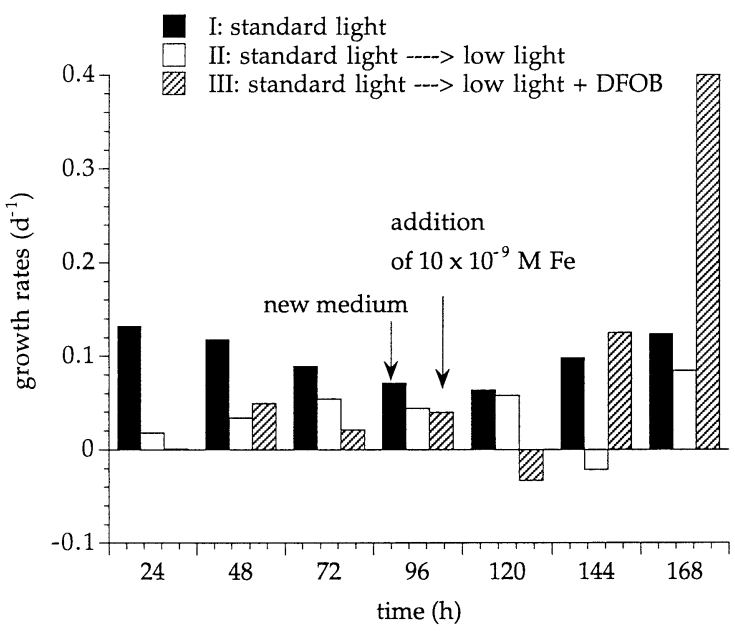

Fig. 4. Chaetoceros brevis (Expt EI-III): Changes in (A) chlorophyll fluorescence (flow cytometer parameter FL3) and (B) growth rates in a standard HL regime (Expt EI: 12:12 h light:dark, $80 \mu \mathrm{mol}$ photons $\mathrm{m}^{-2} \mathrm{~s}^{-1}$, black bars), after a shift to LL (Expt EII: $20 \mu \mathrm{mol}$ photons $\mathrm{m}^{-2} \mathrm{~s}^{-1}$, white bars) and after a shift to LL (Expt EIII: $20 \mu \mathrm{mol}$ photons $\mathrm{m}^{-2} \mathrm{~s}^{-1}$, hatched bars) conditions after addition of $7 \times 10^{-9} \mathrm{M}$ DFOB. New medium was added to the control culture at $t=96 \mathrm{~h}$. Expt EIII received a $10 \times 10^{-9} \mathrm{M}$ Fe addition at $t=96 \mathrm{~h}$. Filtered water from RV 'Polarstern' cruise ANT XVI/3 Stn 174, as indicated above (see Fig. 3)

death was further supported by SYTOX staining of the cells (no data shown, Veldhuis et al. 2001). A full recovery in growth rate, to a value even higher than measured in the control culture, was found after $48 \mathrm{~h}$.

\section{DISCUSSION}

The laboratory experiments and shipboard experiments with the 3 diatom species clearly demonstrated the interaction between iron and light. A classic hyperbolic growth response to increases of iron concentrations was observed in all 3 diatom species tested. This response was modified by light intensity as well as light period. Both the maximum growth rates and the values of $K_{\mathrm{m}}$ of Fe for growth of Chaetoceros calcitrans and $C$. brevis were lower under low-light conditions. Similar findings were reported by Sunda \& Huntsman (1997) for diatoms and by Kudo \& Harrison (1997) for Synechococcus.

Besides growth rates, several other cellular characteristics were affected by iron and light. As expected, cellular chlorophyll a fluorescence was directly linked with light intensity. High chlorophyll a fluorescence was observed under low light and vice versa. This response was modified by iron concentrations, with lower cellular chlorophyll a fluorescence at low iron concentrations. This is similar to the response observed in Synechococcus, where Fe stress led to lower cellular chlorophyll a contents (Kudo \& Harrison 1997).

Cell size also varied with light and iron (Sunda \& Huntsman 1997). At high Fe concentrations, Chaetoceros calcitrans cells were twice as large as in the highlight cultures. With decreasing Fe' concentrations, the differences between high- and low-light cultures became smaller. Our results are similar to those reported by Muggli \& Harrison (1997), who reported that both Fe limitation and light limitation lead to reduction in cell volume in Emiliania huxleyi. For C. calcitrans and $C$. brevis, the spinal index, i.e., the side scatter to forward scatter ratio, was directly linked to iron and light. Under unfavorable conditions (either light or iron) the spinal index remained relatively high. Microscopic examination showed that spinal index was related to the number and extent of spines on the cell surface. The smaller cells possessed more/longer spines. More or longer spines may reduce sinking rates and thus reduce loss of cells from the euphotic zone, and/or reduce grazing pressure. Longer residence time in the euphotic zone and reduced grazing pressure are effective depressors of mortality, often ignored ways of increased survival (Smetacek 1999). Alternatively, the spinal index can also be interpreted as a more general measure of refraction or granularity. Under unfavorable conditions the cells may induce more compact internal structures or a rougher surface, the latter possibly associated with increased uptake sites. The responses documented in our study and by others (Muggli \& Harrison 1997, Sunda \& Huntsman 1997) show a multitude of morphological/ physiological changes with iron limitation. Thus, phytoplankton possess a great variety of responses that may alleviate the low growth rate that is a consequence of iron limitation. However, it is clear that there are limits to these adaptations. 
Experiments with relevant phytoplankton species, in relevant culture media, i.e., without surplus artificial complexing agents, are scarce (Gerringa et al. 2000). The shipboard experiments described in this paper are the first experiments ever done with unialgal phytoplankton cultures under natural conditions (no EDTA) and confirm previous findings of shipboard experiments (Timmermans et al. 2001). Both Chaetoceros dichaeta and $C$. brevis are common species in open Southern Ocean waters (Bathmann et al. 1997). The use of natural (untreated) Southern Ocean waters should allow a more realistic assessment of Fe limitation in nature. However, we note that the laboratory experiments under less natural conditions (i.e., with EDTA) gave results very similar to the shipboard experiments.

The shipboard observations that Chaetoceros brevis grew well at the low ambient $\mathrm{Fe}_{\text {diss }}$ concentrations, whereas $C$. dichaeta growth was low at ambient Fe concentrations, make it clear that, assuming that $\mathrm{Fe}$ is the only governing factor, under low iron concentrations $C$. brevis is the superior competitor. Obviously, the small diatom $C$. brevis had a low Fe requirement and was quite indifferent to the light regime, as growth was observed both under the 12:12 and 20:4 h light:dark regimes. Light intensity (HL or LL) on the contrary did affect growth rates, as demonstrated in the laboratory experiments. If resource limitation of growth were the only factor that affected abundance in the sea, then we would expect an absolute dominance of such small diatom species in the Southern Ocean. As field observations show that these small diatoms did not reach high biomass, some other factor must limit net population growth. The most likely factor is grazer control of the population size of the small cells in an iron-limited ecosystem (Price et al. 1994). Shipboard observations support substantial micro- and mesozooplankton grazing activity (Alheit et al. 2000). The large diatom $C$. dichaeta, in contrast, was iron and light limited under ambient Fe and ambient light:dark conditions. This species could only reach high growth rates with increased Fe concentrations in combination with longer light periods. This is consistent with the observations in the field that large diatoms are capable of formations of blooms (Scharek et al. 1999). However, in the Southern Ocean this only will be the case with favorable Fe and light conditions (Smetacek 1999). This observation appears to explain the absence of high numbers of $C$. dichaeta in the $12: 12 \mathrm{~h}$ light:dark regime as observed during the ANT XVI/3 expedition.

Of all variables examined, the most rapid responses to iron limitation and restoration of availability of iron were those of photosystem II efficiency and turnover time (and its reciprocal, the electron transfer rate) as revealed by FRRF measurements. Iron limitation re- duces the number of functional PSII reaction centres, and therefore the quantum efficiency of photosynthesis as manifested by changes in fluorescence characteristics. Iron limitation lowered $F_{\mathrm{v}} / F_{\mathrm{m}}$ in both Chaetoceros dichaeta and $C$. brevis, in agreement with field and laboratory observations (Greene et al. 1994, Kolber et al. 1994, Behrenfeld et al. 1996, Behrenfeld \& Kolber 1999, Maldonado et al. 1999). In general, the $F_{\mathrm{v}} / F_{\mathrm{m}}$ recovered within $24 \mathrm{~h}$ upon addition of surplus Fe. The response of $\sigma_{\text {PSII }}$, i.e., high values under Fe limitation and rapid decrease upon relief from Fe limitation, supports the use of this parameter as an indicator of nutrient limitation (Geider \& La Roche 1994). The turnover time $\tau$ (and $1 / \tau$ ) showed similar rapid response to Fe concentrations. It is important to emphasise that the values of these parameters, used independently, cannot confidently be used to confirm iron limitation. Rather, the observed differences in these parameters between the cultures grown under the various iron treatments and changes which occurred in response to iron amendment revealed the nutritional status of the cultures examined. It is acknowledged that $F_{\mathrm{v}} / F_{\mathrm{m}}, \sigma_{\mathrm{PSII}}$ and $\tau$ also vary in response to $\mathrm{N}$ and $\mathrm{P}$ starvation (Geider \& La Roche 1994), but we feel that the significant differences and changes detected in these parameters strongly support the conclusions made about the nutritional status of cells grown under the different culture conditions.

The use of DFOB very efficiently reduced bioavailable iron, as both Chaetoceros dichaeta and C. brevis grew slower, had lower $F_{\mathrm{v}} / F_{\mathrm{m}}$ values and higher $\tau$ values in the presence of the Fe-immobilizing DFOB. The fact that addition of surplus Fe resulted in a restoration of both fluorescence characteristics and growth rates is seen as a strong indication that the only effect of DFOB was on the availability Fe and not on the availability of other trace elements. The effect of DFOB on the iron availability, and thus on the photosynthetic apparatus and chlorophyll a fluorescence, was also clear in the experiment in which iron removal was combined with lowering light intensity (Expt E, C. brevis). Upon transfer to low-light conditions, the cultures without added DFOB (Bottle EII) were able to increase cellular chlorophyll a fluorescence and thus acclimate to the lower light intensities, most likely by some re-arrangement of internal Fe. In contrast, transfer to low light in combination with addition of DFOB reduced the rate and extent of acclimation of cellular chlorophyll a fluorescence. Only after addition of surplus Fe did fluorescence increase rapidly. However, when the algal cells were relieved from Fe limitation (under the remaining low-light conditions), the new growth conditions led to increased mortality. Thus, some cells were no longer able to resume growth. Other cells were able to resume growth, given the fact that this initial negative 
response of growth rate was followed $24 \mathrm{~h}$ later by increased growth rates. From these experiments with C. brevis, it can be concluded that light limitation decreases the viability of Fe-limited cells. Alternatively, relief from Fe limitation alleviates light limitation. These findings emphasise the strong coupling between Fe and light limitation in marine phytoplankton.

The present results confirm the hypothesised role of iron in structuring Southern Ocean ecosystems (Timmermans et al. 2001). From an ecological point of view, low-iron and low-light conditions will favour growth of small diatoms. However, the populations of these diatoms appear to be kept in check by protozoan grazers in a carbon- and iron-retaining microbial foodweb. With increased iron availability, for example, as the result of an episodic dust event or the upwelling of iron-rich waters, a shift to large diatoms might occur if the light conditions are favourable. In practice, this will be a period of reduced wind velocities, stabilising the water column and reducing the wind-mixed layer.

Acknowledgements. We thank Prof. Victor Smetacek (chiefscientist ANT XVI/3, AWI, Bremerhaven, Germany), and the master and crew of RV 'Polarstern' for their competent support during the cruise. Eden Rue (Institute for Marine Sciences, UCSC, USA) is thanked for providing the conditional stability constant of DFOB for iron. We acknowledge the support from the European Commission's Marine Science and Technology Program (MAST III) under contract MAS3-CT950005 MERLIM (Marine Ecosystem Regulation: Trace Metal and Carbon Dioxide Limitation) and an EU Climate and Environment grant CARUSO (Carbondioxide Uptake by the Southern Ocean) (contract ENV4-CT97-0472). Further support was obtained from the Netherlands Antarctica Programme 'Biological availability of trace elements', a Netherlands Antarctica Programme grant to L.J.A.G., and a NEBROC (cooperation Netherlands and Bremen Oceanographic Institutes) grant to K.R.T. This is NIOZ publication number 3606.

\section{LITERATURE CITED}

Alheit R, Atkinson A, Bathmann U, Meyer-Harms B (2000) Zooplankton in the Antarctic Polar Front. Ber Polarforsch 364:89-90

Bathmann U, Scharek R, Dubischar C, Klaas C, Smetacek V (1997) Chlorophyll and phytoplankton species distribution in the Atlantic sector of the Southern Ocean in spring. Deep-Sea Res II 44:51-68

Behrenfeld MJ, Kolber ZS (1999) Widespread iron limitation of phytoplankton in the South Pacific Ocean. Science 283: 840-843

Behrenfeld M, Bale AJ, Kolber ZS, Aiken J, Falkowski PG (1996) Confirmation of iron limitation of phytoplankton photosynthesis in the equatorial Pacific. Nature 383: 508-511

Boyd PW, Watson AJ, Law CS, Abraham ER, Trull T (2000) A mesoscale phytoplankton bloom in the polar Southern Ocean simulated by iron fertilization. Nature 407:695-702 de Baar HJW, de Jong JTM, Löscher BM, Veth C, Bathmann U, Smetacek V (1995) Importance of iron for plankton blooms and carbon dioxide drawdown in the Southern Ocean. Nature 373:412-415

de Jong JTM, Das den J, Bathman U, Stoll MMC, Kattner G, Nolting RF, de Baar HJW (1998) Dissolved iron at subnanomolar levels in the southern ocean as determined by shipboard analysis. Anal Chim Acta 377:113-124

Falkowski PG, Raven JA (1997) Aquatic photosynthesis. Blackwell Science, Oxford

Geider RJ, LaRoche J (1994) The role of iron in phytoplankton photosynthesis, and the potential for iron-limitation of primary production in the sea. Photosynth Res 39:275-301

Gerringa LJA, de Baar HJW, Timmermans KR (2000) A comparison of iron limitation of phytoplankton in natural oceanic waters and laboratory media conditioned with EDTA. Mar Chem 68:335-346

Greene RM, Geider RJ, Falkowski PG (1991) Effects of iron limitation on photosynthesis in a marine diatom. Limnol Oceanogr 36:1772-1782

Greene RM, Kolber ZS, Swift DG, Tindale NW, Falkowski PG (1994) Physiological limitation of phytoplankton photosynthesis in the eastern equatorial Pacific determined from variability in the quantum yield of fluorescence. Limnol Oceanogr 39:1061-1074

Henley WJ, Lin Y (1998) Growth and photosynthesis of marine Synechococcus (Cyanophyceae) under iron stress. J Phycol 34:94-103

Kolber ZS, Barber RT, Coale KH, Fitzwater SE, Green RM, Johnson KS, Lindley S, Falkovski PG (1994) Iron limitation of phytoplankton in the equatorial Pacific Ocean. Nature 371:145-149

Kolber ZS, Prasil O, Falkowski P (1998) Measurements of variable chlorophyll fluorescence using fast repetition rate techniques: defining methodology and experimental protocols. Biochim Biophys Acta 1367:88-106

Kudo J, Harrison PJ (1997) Effect of iron nutrition on the marine cyanobacterium Synechococcus grown under different N sources and irradiances. J Phycol 33:232-240

Maldonado M, Boyd PW, Price NM, Harrison PJ (1999) Colimitation of phytoplankton growth by iron and light during winter in the subarctic Pacific Ocean. Deep-Sea Res Part II 46:2475-2485

Millero FJ (1998) Solubility of Fe(III) in seawater. Earth Planet Sci Lett 154:323-329

Mitchell BG, Brody EA, Holm-Hansen O, McCain C, Bishop J (1991) Light limitation of phytoplankton biomass and macronutrient utilization in the Southern Ocean. Limnol Oceanogr 36:1662-1677

Muggli DL, Harrison PJ (1997) Effects of nitrogen source on the physiology and metal nutrition of Emiliania huxleyi grown under different iron and light conditions. Mar Ecol Prog Ser 130:255-267

Myers J, Graham JR (1971) The photosynthetic unit in Chlorella measured by repetitive short flashes. Plant Phys 48:282-286

Nelson DM, Smith WO (1991) Sverdrup revisited: critical depths, maximum chlorophyll levels and the control of Southern Ocean productivity by the irradiance-mixing regime. Limnol Oceanogr 36:1650-1661

Price NM, Ahner BA, Morel FMM (1994) The equatorial Pacific Ocean: grazer-controlled phytoplankton populations in an iron-limited ecosystem. Limnol Oceanogr 39: $520-534$

Raven JA (1990) Predictions of Mn and Fe use efficiencies of phototrophic growth as a function of light availability for growth and C assimilation pathways. New Phytol 116:1-17 
Roy RN, Roy LN, Vogel KM, Lawson M, Vogel KM, PorterMoore C, Davis W, Millero FJ (1993a) Thermodynamics of the dissociation of boric acid in seawater at $\mathrm{S}=35$ from 0 to $55^{\circ}$. Mar Chem 44:243-248

Roy RN, Roy LN, Porter-Moore C, Pearson T, Good CE, Millero FJ, Campbell DM (1993b) The dissociation constants of carbonic acid in seawater at salinities 5 to 45 and temperatures 0 to $45^{\circ} \mathrm{C}$. Mar Chem 44:249-267

Scharek R, Tupas LM, Karl DM (1999) Diatom fluxes to the deep sea in the oligotrophic North pacific gyre at Station ALOHA. Mar Ecol Prog Ser 182:55-67

Secher W, McAvoy DC (1992) MINEQL+: a software environment for chemical equilibrium modeling. Comput, Environ Urban Syst 16:65-76

Smetacek V (1999) Diatoms and the ocean carbon cycle. Protist 150:25-32

Sunda WG, Huntsman SA (1997) Interrelated influence of

Editorial responsibility: Otto Kinne (Editor),

Oldendorf/Luhe, Germany iron, light and cell size on marine phytoplankton growth. Nature 390:389-392

Timmermans KR, Leeuwe MA van, de Jong JTM, McKay RML, Nolting RF, Witte HJ, van Ooyen J, Swagerman MJW, Kloosterhuis H, de Baar HJW (1998) Iron limitation in the Pacific region of the Southern Ocean: evidence from enrichment bioassays. Mar Ecol Prog Ser 166: $27-41$

Timmermans KR, Gerringa LJA, de Baar HJW, van der Wagt B, Veldhuis MJW, de Jong JTM, Croot PL, Boye M (2001) Growth rates of large and small Southern Ocean diatoms in relation to availability of iron in natural seawater. Limnol Oceanogr 46:260-266

Veldhuis MJW, Kraay GW, Timmermans KR (2001) Cell death in phytoplankton: correlation between changes in membrane permeability, photosynthetic activity, pigmentation and growth. Eur J Phycol 36:1-13

Submitted: September 4, 2000; Accepted: February 1, 2001 Proofs received from author(s): July 3, 2001 